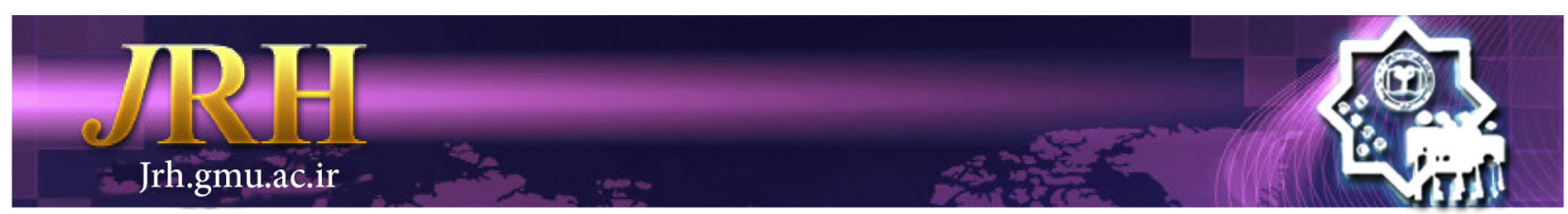

\title{
The effectiveness of brief solution-focused couple therapy (BSFCT) on reducing couple burnout Reza Davarniya ${ }^{1}$, Kianoush Zahrakar ${ }^{1}$, Ali Mohammad Nazari ${ }^{1}$
}

\author{
Journal of Research \& Health \\ Social Development \& Health Promotion \\ Research Center \\ Vol. 8, No. 2, Mar \& Apr 2018 \\ Pages: $123-131$ \\ DOI: 10.29252 jrh.8.2.123 \\ Original Article
}

1. Department of Counseling, Faculty of Psychology and Educational Sciences, Kharazmi University, Tehran, Iran

Correspondence to: Reza Davarniya, Department of Counseling, Faculty of Psychology and Educational Sciences, Kharazmi University, Tehran, Iran

Email: rezadavarniya@yahoo.com

Received: 19 Dec 2013

Accepted: 28 Jan 2014

How to cite this article: Davarniya $\mathrm{R}$, Zahrakar K, Nazari AM. The effectiveness of brief solution-focused couple therapy (BSFCT) on Reducing Couple Burnout. $J$ Research \& Health2018; 8(2): 123- 131.

\begin{abstract}
Brief solution-focused therapy is a collaborative and nonpathological approach for therapy emphasizing on finding the solution by the client with the help and collaboration of the therapist. The research was conducted to examine the effectiveness of brief solution-focused couple therapy in reducing couple burnout among women. The present research has been conducted by a semi-experimental method with a pretest-posttest and follow-up with control group design. The population of the present research included all the women who visited three counseling centers of the welfare organization and also mental helpers. After the initial screening, 30 women, whose scores were the highest in couple burnout questionnaire were selected as the study sample, and they were assigned into two experimental and control groups (15 participants per group). The data were gathered by Pines's couple burnout measure. The level of couple burnout was measured for the experimental and control group participants before experimental intervention (brief solution-focused couple therapy). Afterwards, the experimental group received the brief solution-focused couple therapy for 7 sessions of 1.5-hour in groups, but the control group received no intervention. Also, the experimental group participated in a follow-up session approximately 5 weeks after the last therapy session. Results showed that brief solution-focused couple therapy has been able to significantly reduce couple burnout in the posttest stage and in the follow-up stage. Brief solution-focused couple therapy can be used for reducing marital problems among couples.
\end{abstract}

Keywords: Couple Therapy, Education, Marriage

\section{Introduction}

Marriage is one of the most important needs which nearly affect all the aspects of human life for about half a century. The history of marriage is as old as all history, and by the emergence of human on earth, love and affection, marriage and marriage conflicts have all existed. In fact, the human's mental health is considerably dependent on a good and successful marriage [1]. When people fall in love, most they hope that their love would be eternal and perpetual. This hopefulness is so powerful that can dilute common sense, make the reason hollow and solvable, and blind the eyes in front of the facts and truths. After a while, when 
these individuals meet real life realities and daily problems, they would learn that the truth is different. In this case, it's possible that the couple would get through couple burnout [2].

Burnout is a painful physical, emotional and mental condition, which affects those who expect to have a dreamy love which brings a meaning to their life. Burnout would emerge when they note that despite all their efforts, this relationship has brought no especial meaning and significance to their life and it isn't going to bring any meaning in future [3]. Kayser believed that couple burnout means the gradual reduction of emotional attachment to the spouse, which accompanies feelings of alienation, lack of interest, and indifference of couples towards each other and leads to replacement of positive affections by negative ones [4]. Pinez asserted that burnout is the result of an erosion process in which the committed and motivated individuals lose their spirits [5]. Pines, Neal, Hammer, and Icekson defined burnout as a physical, emotional and mental exhaustion which are resulted from a prolonged conflict and was accompanied by many emotional demands. In this definition, physical exhaustion is characterized by energy reduction, chronic tiredness, weakness, and a broad variation of physical and psychosomatic complains. While emotional exhaustion includes feelings of helplessness, frustration and deception, mental exhaustion is accompanied by development of negative attitude toward self, job and life [6]. Since couple burnout leads to reduction in love and affection and increase in hostile behaviors, therefore it can cause marital dissatisfaction and undermine the family foundations [7].

One of the effective therapeutic interventions for helping the couples who struggle with couple burnout is brief solution-focused therapy. Brief solution-focused therapy is one of the branches of postmodern approach in the family therapy domain which solves the problems by focusing on problem-solving, change and attention to the solutions [8].

Insoo Kim Berg and Steve De Shazer in the brief family therapy center (BFTC), in Milwaukie and Wisconsin, developed the brief solution- focused therapy [9]. In this approach, in contrast to the problem-focused perspective, finding solutions is emphasized instead of focusing on problems [10]. Therefore, the solution-focused therapy is based on constructing solutions instead of solving the problems, and this approach is guided through discovering the client's strengths and hopefulness towards future, not through discussion on the existing problems and their causes in past [11]. The therapeutic method argued that the clients have the required competencies and creativities for change within themselves [12]. The framework of solution-focused therapy is focused on strength and attempts of the client for the purpose of helping him/her to create positive solutions and get out of problem [13].

Solution-focused therapists believe that couples' problems persist and deteriorate because of the method the couple try to solve them. Solution-focused couple therapy reminds the couples of the problem-solving skills when necessary, enables the couples to destroy the vicious circle of the problem, and develop long-term solutions [14]. In this therapy the focus is on the problems for which there is a probability for change not on tough and unchangeable grounds. Thus, solution-focused therapy has been recognized as hopefulness counseling [15].

Research indicates that this approach can lead to desirable outcomes and perform well even in emergency cases [16]. The studies carried out in brief family therapy center in Milwaukee report on range of 0.72- 0.80 success for treatment of clients' problems [17].

Russell has investigated the effectiveness of solution-focused therapy on marital adjustment. The marital adjustment scale of Spanier has been used in this investigation. Statistical analyses on the data indicated that this therapy approach significantly increases all of four components of this scale, which include marital satisfaction, solidarity, agreement and expression of affection [18]. Johnson and Lebow selected a group of couples 
for the purpose of increasing their relationship satisfaction and enhancing relationship quality and problem-solving methods among them, and provided solution-focused therapy for them. Results suggested that solution-focused therapy leads to improvement in couples' relationships [19]. In a research conducted by Nelson and Kelley, solution-focused group therapy helped 5 couples out of 7 to increase their relationship satisfaction [20].

Couple burnout is another common marital problem with which many couples are faced. Those who suffer couple burnout feel that they have been emotionally destroyed, they are resented and discouraged, and they have no interest to explain anything or to take a step towards solving their problems. They believe that no sign of hope has been left for them in their relationship. Since this phenomenon is accompanied by feelings such as anger, hopelessness, and frustration towards the spouse, and culmination of such painful feelings gradually leads to disaffection and dissatisfaction from the spouse and make the life alongside the spouse intolerable; therefore, its timely treatment are of great importance for the couple system by considering this phenomenon and its destructive consequences. Since solution-focused therapy has gained effective therapeutic outcomes in various researches as a brief therapy in working with couples struggling with different problems, and this approach has been able to help in couple adjustment and marital relationship improvements, and since little research has been conducted on marital burnout, and also according to the fact that no research has been conducted in inside or outside Iran on investigating the effect of this therapeutic approach on reducing couple burnout, therefore, the present research was conducted to investigate the effectiveness of brief solution-focused therapy in reducing couple burnout among women.

\section{Method}

The research method is semi-experimental with pretest-posttest and follow-up with control group design. The population included all the women residing in Bojnourd, Iran, who visited three counseling centers of the welfare organization, and also mental helpers center in Bojnourd city, Iran, for the purpose of receiving professional marital help in the summer of 2013; their visit took place after an appeal which was made by the researchers for holding a treatment course for reducing marital problems.

After a one-month preparatory interval for registration and getting prepared for participation in treatment session, 73 women declared their readiness to participate in the session, among which 60 women were qualified based on the study inclusion criteria. The inclusion criteria included: being married, having at least 5 years of marriage experience, 30-50 years of age range, commitment to participate in all the couple therapy sessions, and receiving no individual counseling and psychological intervention during their participation in the research course. These individuals were selected by purposeful method, and they completed Pines's Couple Burnout Measure. The exclusion criteria were consumption of psychiatric medication and addiction. Based on the results gained by the initial test, 30 women with highest scores for couple burnout were selected as the study sample, and in the nest stage, they were assigned in two groups of experiment and control (15 participants per group) by random assignment method. The protocol of treatment sessions was developed based on the couple therapy model of Zimmerman, Prest and Wetzel, and the group therapy model of Nazari. After performing the pretest for both groups, the brief solution-focused couple group therapy sessions were held for seven 1.5-hour weekly sessions for the experiment group; the sessions were held in groups with a step-bystep format. The control group received no therapeutic intervention. After finishing the interventions, both groups took posttest, and one month after the intervention sessions, the follow-up test was performed for both groups for the purpose of assessing the durability of 
the treatment effect (brief solution-focused couple therapy). After the follow-up stage, for meeting principles of research ethics, a one-day brief solution-focused couple therapy workshop was held for the control group. A summary of brief solution-focused couple therapy sessions is presented in Table 1 [31,32].

Table 1 The structure of brief solution-focused therapy couple therapy sessions

\begin{tabular}{|c|c|}
\hline $\begin{array}{c}\text { Session } \\
\text { numbers }\end{array}$ & Sessions' descriptions \\
\hline Session 1 & $\begin{array}{l}\text { Performing pretest - aim: getting acquaintance among the group members and the therapist. Describing the } \\
\text { group rules, determining frameworks, and introducing general principles of brief solution-focused couple } \\
\text { therapy. Task: participants were expected to write down their purposes for participation in sessions and present } \\
\text { them to the group in the following session. These purposes must be focused on the changes which would be } \\
\text { made in the group. }\end{array}$ \\
\hline Session 2 & $\begin{array}{l}\text { Aim: helping the participants to develop their own purposes in a positive, clear, tangible and measurable way. } \\
\text { Task: participants were asked to write down additional purposes and expectations they have from themselves, } \\
\text { spouse, and their lives in a positive, exact, tangible and measurable way and bring them for the nest session. }\end{array}$ \\
\hline Session 3 & $\begin{array}{l}\text { Aim: helping the clients to learn that there are different interpretations for the same event in the family, and } \\
\text { to learn to change their interpretation of the problems in a more helpful way. Helping them to know their own } \\
\text { resources and capabilities and to learn to admire one another. Task: the group members were asked to refrain } \\
\text { from criticizing their spouse in any circumstance, and instead, admire and compliment any positive action } \\
\text { done by their spouse and report them all in the following session. }\end{array}$ \\
\hline Session 4 & $\begin{array}{l}\text { Aim: helping the participants to identify positive exceptions in their marital life, accordingly find hope in their } \\
\text { lives, and be able to reduce their scope of problems. Task: the participants were asked to think more over the } \\
\text { proposed questions, identify positive exceptional moments of their lives and report back in the following session. }\end{array}$ \\
\hline Session 5 & $\begin{array}{l}\text { Aim: eliminating the disturbed behavioral patterns by using miracle questions. } \\
\text { Tasks: the participants were asked to think over the proposed question at home and bring their questions in the } \\
\text { following session. }\end{array}$ \\
\hline Session 6 & $\begin{array}{l}\text { Aim: helping the members to find alternative ways of thinking, feeling, and behaving other than what they } \\
\text { currently do, and experience new feelings by using the important term "instead". Task: the participants } \\
\text { were asked to toss a coin in a specific hour every day. The winner can complain from his/her spouse for } 10 \\
\text { minutes, after which, the other spouse (the loser) can complain for } 10 \text { minutes. They were asked to report the } \\
\text { complaints' results in the following session. }\end{array}$ \\
\hline Session 7 & $\begin{array}{l}\text { Summarization, conclusion, and exploring if the members have gained their purposes or not? } \\
\text { Performing the posttest } \\
\text { Coordination for holding the follow-up session in the following month }\end{array}$ \\
\hline
\end{tabular}

In this research tools included:

Pines' couple burnout measure (CBM): in the present research, couple burnout measure of Pines with 21 questions has been used for measuring couple burnout. In this scale, higher scores show greater burnout, the top score is 147 and lowest score is 21 . For interpreting the scores, they must be converted into degrees; this process involves dividing the obtained scores by the total questions ( 21 questions). While interpreting the score, the degrees greater than 5 indicate the necessity of emergency help, degree 5 indicates the presence of crisis, degree 4 shows a burnout state, degree 3 indicates the risk for burnout, and degree 2 and lower indicate a good relationship. Test-retest reliability was 0.89 for a one-month course, 0.76 for a two-month course, and 0.66 or a three-month course. The obtained Alpha coefficient has been reported to be between 0.91 and 0.93 . In Iran, Navidi has reported the reliability of this questionnaire to be 0.86 by using Cronbach alpha [33]. In the present research also, the internal consistency by measuring Cronbach alpha has been 78.9.

The data analysis was conducted by SPSS- 18 . In the descriptive statistics level, the following indices were used: frequency, mean, and standard deviation. In the inferential statistics level, univariate covariance analysis test was used.

\section{Results}

The mean age of the participants was $38.53 \pm 5.8$, and their marriage duration mean was $14.23 \pm 5.92$. Regarding the education level, $20 \%$ had elementary degree, $36.6 \%$ had secondary school degree, $26.6 \%$ had diploma, 
and $16.8 \%$ had associate degree.

In Table 2, descriptive indices of both experiment and control groups are presented in three stages

of pretest, posttest and follow-up.

\begin{tabular}{lcccccc}
\multicolumn{6}{l}{ Table 2 Mean and standard deviation of experiment and control groups for the couple burnout variable } \\
\hline Groups & Pretest & \multicolumn{5}{c}{ Posttest } \\
\hline Mean & $\begin{array}{c}\text { Standard } \\
\text { deviation }\end{array}$ & Mean & $\begin{array}{c}\text { Standard } \\
\text { deviation }\end{array}$ & Mean & $\begin{array}{c}\text { Standard } \\
\text { deviation }\end{array}$ \\
\hline Experiment & 106.66 & 21.37 & 82.6 & 17.76 & 82.55 & 21.89 \\
Control & 101.26 & 15.29 & 102.86 & 5.9 & 100.6 & 8.03 \\
\hline
\end{tabular}

For conducting the covariance test, the following assumptions are required: the normal distribution of scores, homogeneity of variances, and homogeneity of the regression slope. For examining the normality of scores' distribution, the Kolmogorov-Smirnov test was used. Results of this test suggest that the distribution of scores for pretest $(p>0.05$ and $Z=0.595)$ and posttest $(p>0.05$ and $Z=0.655)$ is normal. For examining the homogeneity of the variances, Leven's test was used, and according to lack of significance of Leven's test for pretest and posttest ( $p>0.05$ ), it can be concluded that the assumption of homogeneity of variances is established.

Table 3 Results of variance homogeneity and normality of scores' distribution tests for the couple burnout variable in the experiment and control groups

\begin{tabular}{lcccccccc}
\hline & $\begin{array}{c}\text { Leven's } \\
\text { test }\end{array}$ & \multicolumn{7}{c}{$\begin{array}{c}\text { Kolmogorov- } \\
\text { Smirnov test }\end{array}$} \\
\hline Pretest & Leven test & Df1 & Df2 & Sig & Mean & SD & Z & Sig \\
Posttest & 1.369 & 1 & 28 & 0.252 & 103.96 & 18.47 & 0.595 & 0.871 \\
\hline
\end{tabular}

Table 4 Results of examination of homogeneity of the regression slope

\begin{tabular}{lccccc}
\hline Source of variation & Sum of squares & Degree of freedom & Mean of squares & F-test & Significance level \\
\hline $\begin{array}{l}\text { Effect of group's } \\
\text { interaction with pretest }\end{array}$ & 575.752 & 2 & 287.876 & 1.04 & 1.02 \\
Error & 7473.708 & 27 & 276.804 & & \\
\hline
\end{tabular}

For investigating lack of interaction between the groups and pretest scores, the assumption of homogeneity of regression slopes was examined, and according to the results this assumption was confirmed ( $>0.05, F 1$, $28=1.04)$. Therefore, it can be concluded that there is no interaction between the groups and the pretest.

Table 5 Results of one-way covariance analysis (ANCOVA) for investigating the effect of test and follow-up in couple burnout variable

\begin{tabular}{lccccccc}
\hline $\begin{array}{l}\text { Source of } \\
\text { variation }\end{array}$ & $\begin{array}{c}\text { Sum of } \\
\text { squares }\end{array}$ & $\begin{array}{c}\text { Degree of } \\
\text { freedom }\end{array}$ & $\begin{array}{c}\text { Mean of } \\
\text { squares }\end{array}$ & F test & $\begin{array}{c}\text { Significance } \\
\text { level }\end{array}$ & Effect-size & $\begin{array}{c}\text { Statistical } \\
\text { power }\end{array}$ \\
\hline Pretest effect & 1141.782 & 1 & 1141.782 & 4.263 & 0.017 & 0.253 & \\
Group effect & 3011.434 & 1 & 3011.434 & 11.236 & 0.002 & 0.294 & 0.896 \\
$\begin{array}{l}\text { Error } \\
\text { Follow-up }\end{array}$ & 7236.655 & 27 & 268.024 & & & & \\
effect & 2157.82 & 1 & 2157.82 & 7.98 & 0.009 & 0.226 & 0.908 \\
Error & 7376.93 & 27 & 273.22 & & & & \\
\hline
\end{tabular}

According to the result of one-way covariance analysis, presented in Table 5, the significance of the $F$-value $(F=11.236$ and $p<0.01)$ suggests that the group effect is significant, that is, after calculating the effect of pretest the difference of the experiment and control groups in couple burnout level is significant. Also, according to results of table 2 , in posttest and follow-up stages, mean scores of couple burnout in the experiment group are lower than the control 
group, which suggests the effectiveness of the treatment model on reducing couple burnout.

The effect value of brief solution-focused couple therapy on couple burnout has been 0.294 in posttest, that is, about 29 percent of the variance in total remaining scores is related to the group membership or the effect of treatment. Also, F-value in the follow-up stage $(\mathrm{F}=7.98$ and $\mathrm{p}<0.01)$ shows that the treatment effect has been consistent for one month after ending the treatment. The statistical power in posttest and follow up stages (0.89 and 0.90, respectively) indicates an acceptable statistical power.

\section{Discussion}

The present research was conducted by the aim of investigating the effectiveness of brief solution-focused couple therapy in reducing couple burnout among women. Research findings indicate that brief solution-focused couple therapy has led to reduction in couple burnout among the women in the experiment group, and there is a significant difference between the women who received solutionfocused couple therapy and the women who did not receive intervention. Also, findings suggest that the effect of brief solution-focused couple therapy has been consistent for one month after the intervention and in the follow-up stage.

Findings of the current research are consistent with the following studies: Stewart's research which showed that solution-focused couple therapy is effective on increasing relationship satisfaction, improving communicational skills and individual functions of couples; Eakes and colleagues research which indicated that solution-focused therapy changes the attitude of couples towards difficult conditions, creates a more positive view towards problems in couples, and strengthens their capabilities for coping with difficulties and problems [34, 35]. In a research conducted by Christiansen on 24 couples, it was found that therapeutic experiences created by solution-focused approach have led to certain changes in their emotions, relationships and cognitions in their couple relationships [31]. Zimmerman, Prest and Wetzel investigated the effectiveness of solution-focused group couple therapy on increasing adjustment and improving marital condition, and they found that solutionfocused group couple therapy is able to reduce aggressiveness and sexual problems in couples and improves time for togetherness and agreement on financial issues [24]. Also, research findings are consistent with findings of Murray and Murray, and Davodi and colleagues [19,37].

Solution-focused therapy is a post-modern approach in couple therapy and family therapy, in which therapists, in their assumptions and investigations, believe in their clients' strength and capability for creating exceptions, achieving goals, and linking the solutions with life [38].

Couples often respond to one another without thinking, and they persist in continuing their behavior without getting favorable results. Solution-focused therapists help the couples to stop blaming each other for the problems, start emphasizing on cognition, change the useless patterns and reach a better balance [21]. Solution-focused couple therapy is focused on exceptions to the inappropriate matters which are shaped in relationships. The solution-focused therapists asks questions about the times that no problem existed and the view of the clients about focusing on all the details of the current problem. Exception questions try to discover the times when no problem existed, coping with the problem was easier, or the problem was less severe. For instance, the therapist asks the couples, when was the last time that you listened to your spouse? What times are easier for you not to quarrel with your spouse? Have you had times that you two have enjoyed each other? The form of exception questions imply that exceptions always exist [25]. The therapist helps the couples to determine what they have done wrong at what time, without ignoring or escalating the problem [39].

In solution-focused couple therapy, couples are encouraged to do positive things that they have done more in positive times 
than negative times. Exceptions can be even recognized or extracted from the discussions of couples. The couples who have difficulty in identifying current exceptions are asked to remember what they have done in past that led to marital satisfaction in them, and then reestablish those actions and behaviors that they have done in past [40]. During the work, the therapist can help the clients in creating a significant and visible change. Since couples can see the changes or change potentials in their lives, therefore, solution-focused couple therapy introduces the idea of control to the couples. This active control and cooperation in treatment allows the clients to feel controlling their problems and guiding their actions [39].

In addition to exceptions, miracle question is another interventional question for solutionfocused therapists. Miracle question helps to find information on the client's view about future or a solution to the problem. The solutionfocused therapist asks the client is a miracle happens today and all your problems are solved, what would you do which is different? Who do you recognize that the problem has been solved? Using such questions helps the clients to find a different way of looking at their problems and it can be an important step in the change process [41]. In scaling questions, also, the therapist asks the clients to rate the level of their problems on a scale of 1 to 10 . These questions help the clients to identify the progress or lack of progress for a particular problem in or outside the treatment [42].

By using various techniques, brief solutionfocused couple therapy tries to remind the couples of the beautiful and memorable moments which have been often forgotten in the marital relationship, and remind them that they can create and experience such beautiful moments again. Among the limitations of the present research is the self-reporting nature of the research tool, which must be considered. Also, the gender role has not been considered in the present research, and it has been limited to housewives. Since the present research has been conducted in Bojnourd city, therefore, generalizing the findings must be done with caution.

\section{Conclusion}

Findings of the present research indicated that brief solution-focused couple therapy has been able to reduce couple burnout in women. When romantic expectations are not met in the marital relationship, the frustration feeling is directly attributed to the spouse, then it leads to reduction in love and commitment, and burnout would replace love. Marital burnout in couples makes many couples discouraged from continuing their married life, brings about emotional and mental separation among the couples, and fades away their excitement for being with their life partner. Currently, in the discussions on couple therapy and family therapy, more attention has been paid to brief therapy models able to help clients in shorter periods. Solution-focused therapy as a brief and post-modern therapeutic interventions, has been able to gain successful therapeutic outcomes in various researches. Since the main emphasis in this approach is on finding solutions by clients, those clients who always see themselves trapped in problems gain a new view on facing with problems. This new perspective creates a kind of hopefulness about self and future in clients. Additionally, due to the brief nature of the therapy process, this therapeutic approach can be useful for those clients who want to reach desirable conditions in shorter periods. It is recommended that the effectiveness of this approach would be compared to other existing approaches in this background. Additional research should also be conducted on male participants, and appropriate therapeutic criteria for men should be identified through empirical research. Training, supervision and continuing education for counselors, family therapists and marriage counselors in this therapeutic approach are among other recommendations of the present research. It is also recommended that this approach would be used in family training courses and couple/family therapy groups for improving marital relationships and preventing future problems in couples. 


\section{Acknowledgements}

The research group is obliged to express their highest respect and gratitude to all the authorities of counseling centers and participant who assisted us in conducting the present research. The current research is extracted from a dissertation for master's degree in Kharazmi University of Tehran which has been confirmed in research council of the faculty and belongs to the corresponding author.

\section{Contribution}

Study design: RD, KZ, AMN

Data collection and analysis: RD, KZ, AMN

Manuscript preparation: RD, KZ, AMN

\section{Conflict of Interest}

"The authors declare that they have no competing interests."

\section{Funding}

The author (s) received no fnancial support forthe research, authorship and/or publication of this article.

\section{References}

1- Sanai B. Marriage: motives, cliffs and its health. Educational Researches 1999; 384(4): 19- 43.

2- Bahrami F, Rezvan Sh. Sexual infidelity and its psychological factors. In: Sanai B, Bactash M, eds. The battery of family and marriage counseling's articles of fifth conference of Iran counseling institute. Tehran: Anjoman olia morabbian publication; 2004. pp: 141-53. 3-Ahmadi M, Zahrakar K, Davarniya R, Rezaiee M. The effectiveness of brief self-regulation couple therapy on couple burnout in couples of Saveh city. Razi Journal of Medical Sciences2016; 22(139): 64-75.

4- Kayser K. The marital disaffection scale: An inventory for assessing motional estrangement in marriage. $\mathrm{Am} J$ Fam Ther1996; 24(1): 68-80.

5- Pinez A M. Couple burnout: courses \& cures. London: Routledg; 1996. pp: 1-27.

6- Pines AM, Neal MB, Hammer LB, Icekson T. Job burnout and couple burnout in dual- earner couples in the sandwiched generation. Soc Psychol Q2011; 74(4): 361-86. 7- Huston T. What is love got to do with it? why some marriage succeed and other fail. Journal of Personal Relationship2009; 16(3): 301-27.

8- Becvar DS, Becvar RJ. Family therapy: A systemic integration. 5th ed. Needham Heights, MA: Allyn \& Bacon; 2003. pp: 84-5.

9- Gong M. Does status in consistency matter for marital quality? J Fam Issues2007; 28(12): 1582-610.
10-Brzezowskl KM. A solution-focused group treatment approach for individuals maladaptively expressing anger. [dissertation]. Ohio: Wright State University 2012. pp: 55-7.

11- Wand T. Mental health nursing from a solution focused perspective. Int J Ment Health Nurs2010; 19(3): 210-19.

12- Cheung S. Strategic and solution focused therapy. Handbook of couple therapy. New Jersey: John Wiley; 2005. pp: 141-43.

13- Murray CE, Murray TL. Solution focused premarital counseling: Helping couples build a vision for their marriage. J Marital Fam Ther2004; 30(3): 349-58.

14- Jenny Steele J. Applying an integration of solution focused therapy and Family of origin therapy models in working with couples. [dissertation]. Manitoba: University of Manitoba Winnipeg 1997. pp: 44-5.

15- Nunnally T. Solution - focused therapy. Case book of the brief psychotherapies. New York: Plenum; 1993. pp: 91-3.

16- Lee MY. A study of solution-focused brief family therapy: outcomes and issues. Am J Fam Ther1997; 25(1): 3- 17 .

17- Nazari A, Goli M. The effects of solution-focused psychiatry on marriage satisfaction of couples who both work. Journal of Knowledge \& Health2007; 4(2): 36-40. 18- Russell M. Equine facilitated couples therapy and solution focused couples therapy: A comparison study. [dissertation]. Prescott, Arizona 2006. pp: 44-5.

19- Johnson S, Lebow J. The "coming of age" of couple therapy: A decade of review. J Marital Fam Ther2000; 26(1): 23-38.

20- Nelson TS, Kelley L. Solution-focused couples group. J Syst Ther2001; 20(4): 47-66.

21- Zimmerman TS, Prest LA, Wetzel BE. Solutionfocused couple therapy groups: An empirical study. $J$ Fam Ther1997; 19 (2):125-44.

22- Nazari AM. A study of effectiveness of relationship enrichment program and solution- focused counseling on marital satisfaction among dual career couples. [dissertation]. Iran: Tarbiat Moallem University of Tehran 2004. pp: 56-7.

23- Navidy F. Study and comparison of couple burnout relationship with organizational climate factors in employee education and hospitals of Tehran nurses. [dissertation]. Iran: Shahid Beheshti University of Tehran 2005. pp: 39-40.

24- Stewart JW. A pilot study of solution-focused brief therapeutic intervention for couples. [dissertation]. Logan,USA: Utah State University 2011. pp: 48-50.

25- Eakes G, Walsh S, Markowksi M, Cain H, Watson M. Family cantered brief solution focused therapy with chronic schizophrenia: A pilot study. J Fam Ther1997; 19(2): 145- 8 .

26- Christensen LL, Russell CS, Miller RB, Peterson CM. Process of change in couples therapy: A qualitative investigation. J Marital Fam Ther1998; 24(2): 177-88. 27- Davodi Z, Etemadi O, Bahrami F, Shahsiah M. The 
effect of brief solution-focused couple therapy approach on couples' marital adjustment in men and women prone to divorce in 2010-2011 in Isfahan. Journal of Fundamentals of Mental Health2012; 14(55): 190-9.

28- Seedall RB. Enhancing change process in solutionfocused brief therapy by utilizing couple enactments. Am J Fam Ther2009; 37(2): 99-113.

29- Mudd J. Solution focused therapy and communication skills training: An integrated approach to couples therapy. [dissertation]. Blacksburg: Virginia Polytechnic Institute 2000. pp: 61-2.

30- Weiner-Davis M. Divorce busting. Toronto: Simon and Schuster 1992. pp: 124-9.

31- De Castro S, Guterman JT. Solution-focused therapy for families coping with suicide. J Marital Fam Ther2008; 34(1): 93-106.

32- Lethem J. Brief solution focused therapy. Child Adolesc Ment Health2002; 7(4): 189-92.

\footnotetext{
Copyright(C) 2016 ASP Ins. This open-access article is published under the terms of the Creative Commons Attribution-NonCommercial 4.0 International License which permits Share (copy and redistribute the material in any medium or format) and Adapt (remix, transform, and build upon the material) under the Attribution-NonCommercial terms.
} 